\title{
VAPORIZAÇÃO DE ÁCIDO ACÉTICO PARA O CONTROLE PÓS-COLHEITA DE Botrytis cinerea EM UVA 'ITÁLIA'
}

\author{
ELISANGELA CLARETE CAMILI ${ }^{2}$, ELIANE APARECIDA BENATO ${ }^{3}$, \\ SÉRGIO FLORENTINO PASCHOLATI ${ }^{4}$, PATRÍCIA CIA ${ }^{5}$
}

RESUMO - Visando a avaliar o efeito do vapor de ácido acético (AA) como medida alternativa no controle pós-colheita do mofo-cinzento (Botrytis cinerea) em uva 'Itália', foram conduzidos dois ensaios in vivo onde se avaliou o efeito direto e indireto do AA através do tratamento dos cachos antes e após a inoculação do patógeno, sendo: 1) cachos de uva foram inoculados e, após $4 \mathrm{~h}$, vaporizados com AA $(0,0 ; 0,25 ; 0,5$; 1,0 ou $2,0 \mathrm{~mL} 100 \mathrm{~L}^{-1}$ vol. de câmara) em tambores herméticos $(200 \mathrm{~L})$, a $25 \pm 1{ }^{\circ} \mathrm{C} / 70-80 \% \mathrm{UR}$, por 30 min; 2) cachos foram, ou não, vaporizados com AA (1 mL $100 \mathrm{~L}^{-1}$ vol. de câmara) e, após 24; 48; 72 ou 96 $\mathrm{h}$, inoculados com B. cinerea. Para inoculação, em cada cacho, 10 por tratamento, foram feridas 10 bagas, fazendo-se um furo por baga de $\pm 2 \mathrm{~mm}$ de profundidade, procedendo-se, em seguida, aspersão de suspensão de esporos $\left( \pm 10^{5}\right.$ conídios $\left.\mathrm{mL}^{-1}\right)$. Após os tratamentos, os cachos foram mantidos a $25 \pm 1{ }^{\circ} \mathrm{C} / 80-90 \% \mathrm{UR}$ e avaliados diariamente quanto à incidência e severidade da podridão. O efeito in vitro do vapor de AA no controle do patógeno foi avaliado com o intuito de verificar se tal agente estaria exercendo efeito direto sobre o crescimento micelial e a germinação de conídios de $B$. cinerea. Nos ensaios in vivo, o vapor de AA controlou a podridão de $B$. cinerea em uva 'Itália', nos cachos inoculados antes ou após o tratamento com AA, sendo as uvas inoculadas $48 \mathrm{~h}$ após o tratamento, as que apresentaram menor índice de doença. In vitro, o AA exerce efeito direto sobre o crescimento micelial e a germinação de conídios de $B$. cinerea.

Termos para indexação: Vitis vinifera L., mofo-cinzento, controle alternativo.

\section{FUMIGATION OF 'ITALIA'GRAPE WITH ACETIC ACID FOR POSTHARVEST CONTROL OF Botrytis cinerea}

\begin{abstract}
Two in vivo trials were carried out in order to evaluate the effect of acetic acid vapor (AA) as an alternative for postharvest control of gray mold (Botrytis cinerea) in 'Itália' grapes. The direct and indirect effect of AA over treated bunches before and after pathogen inoculation was evaluated. In trial 1, grape bunches were inoculated and after $4 \mathrm{~h}$ submitted to AA vapors $(0.0,0.25,0.5,1.0$ or $2.0 \mathrm{~mL})$ in hermetic chambers $(200 \mathrm{~L})$, at $25 \pm 1{ }^{\circ} \mathrm{C} / 70-80 \% \mathrm{RH}$, for $30 \mathrm{~min}$. In trial 2, grape bunches were vaporized or not with AA $\left(1 \mathrm{~mL} 100 \mathrm{~L}^{-1}\right)$ and after $24,48,72$ or $96 \mathrm{~h}$, inoculated with $B$. cinerea. For inoculation, in each bunch (10 per treatment) 10 berries were injured with a $\pm 2 \mathrm{~mm}$ deep puncture and sprayed with a spore suspension $\left( \pm 10^{5}\right.$ conidia $\left.\mathrm{mL}^{-1}\right)$. After treatments, bunches were stored at $25 \pm 1{ }^{\circ} \mathrm{C} / 80-90 \% \mathrm{RH}$ and daily evaluated regarding rot incidence and severity. The in vitro effect of AA vapor on pathogen control was evaluated in order to verify if this agent would directly affect mycelia growth and $B$. cinerea conidia germination. In the in vivo trials, AA vapor control $B$. cinerea rot in 'Italia' grape in bunches inoculated before and after treatment with AA. Grapes inoculated $48 \mathrm{~h}$ after treatment with AA showed the lowest disease incidence index. In vitro AA has a direct effect on mycelia growth and conidia germination of $B$. cinerea.
\end{abstract}

Index terms: Vitis vinifera L., gray mold, alternative control.

\footnotetext{
${ }^{1}$ (Trabalho 117-09). Recebido em: 15-05-2009. Aceito para publicação em: 11-11-2009.

${ }^{2}$ Professora Adjunta do Departamento de Fitotecnia e Fitossanidade da Faculdade de Agronomia e Medicina Veterinária-FAMEV da Universidade Federal de Mato Grosso-UFMT. Av. Fernando Corrêa, s/nº, Coxipó, 78060-900, Cuiabá/MT. ecamili@ufmt.br

${ }_{3}^{3}$ Pesquisadora Científica do Instituto de Tecnologia de Alimentos - ITAL. Av. Brasil, 2880, Jd. Chapadão, 13070-178, Campinas/SP. benato@ital.sp.gov.br

${ }^{4}$ Professor Associado do Departamento de Fitopatologia da Escola Superior de Agricultura "Luiz de Queiroz" - ESALQ/USP. Av. Pádua Dias, 11, CP. 09, 13418-900, Piracicaba/SP. sfpascho@esalq.usp.br

${ }_{5}^{5}$ Pesquisadora Científica do Centro de Engenharia e Automação (IAC). Rod. D. Gabriel P. B. Couto, Km 65, CP. 26, 13201-970, Jundiaí/SP.pcia@iac.sp.gov.br
} 


\section{INTRODUÇÃO}

Embora as uvas de mesa possam ser armazenadas por longos períodos, apresentam maiores dificuldades de conservação quando comparadas a outras frutas, devido à sua alta suscetibilidade à desidratação e ao desenvolvimento de fungos causadores de podridões (GONZALEZ, 2003), além dos danos mecânicos, originados na colheita, manuseio e/ou transporte. Se estes fatores de deterioração não forem bem controlados, o potencial de conservação diminui, e as perdas tornam-se significativas (BENATO, 2002).

Nas condições de armazenamento requeridas pelas uvas de mesa, com alta e constante umidade, os prejuízos causados pelas podridões são consideráveis, sendo o desenvolvimento de fungos durante o armazenamento e/ou transporte a maior causa de perdas (MARQUENIE et al., 2002). Botrytis cinerea, agente causal do mofo-cinzento, é a espécie fúngica de maior incidência (DIAS et al., 1998; BULIT; DUBOS, 1990), tornando-se indispensável o tratamento dos cachos após a colheita, visando à prevenção de podridões.

Diante da restrição crescente ao uso de produtos químicos em pós-colheita, tem ocorrido um considerável interesse por métodos alternativos de controle de doenças, que possuam mecanismos capazes de promover a indução de resistência nos tecidos vegetais a patógenos ou que possam complementar ou substituir o uso de fungicidas e prolongar o período de armazenamento dos frutos (CIA et al., 2007).

A fumigação não é amplamente utilizada como método para controle de doenças em póscolheita embora apresente propriedades úteis. Os fumigantes podem difundir-se e penetrar em espaços que são inacessíveis aos pesticidas líquidos ou sólidos e exercer seu efeito durante o período de exposição, mas, por ser difusível, deixa pouco ou nenhum resíduo, necessitando de constantes ou sucessivas aplicações. A uva de mesa é comercialmente fumigada para prevenção de doenças pós-colheita. Para tanto, emprega-se geralmente o dióxido de enxofre $\left(\mathrm{SO}_{2}\right)$, que, dependendo da cultivar, temperatura e umidade de armazenamento, entre outros fatores, pode apresentar diferenças quanto à eficiência e aos níveis de resíduo, cujo limite de tolerância permitido é de $10 \mu \mathrm{g} \mathrm{g}^{-1}$ (FDA, 2003).

No contexto dos fumigantes (ou voláteis) com possibilidade de utilização em pós-colheita, o ácido acético, um intermediário metabólico que ocorre naturalmente em muitos frutos (MOYLS et al., 1996), em baixas concentrações, não é inflamável, explosivo ou carcinogênico (SHOLBERG et al., 2001), sendo um composto estável utilizado em inúmeros processos industriais, podendo ser promissor quando empregado na forma de vapor, para o controle póscolheita de patógenos (SHOLBERG;GAUNCE, 1996).

Estudos prévios (SHOLBERG; GAUNCE, 1995; SHOLBERG;GAUNCE, 1996; SHOLBERG et al., 1996) mostraram que o vapor de ácido acético em concentrações relativamente baixas pode inibir completamente os esporos de vários fungos patogênicos presentes na superfície dos frutos. Sholberg e Gaunce (1995) demonstraram que a aplicação pós-colheita de baixas concentrações de vapor de ácido acético $\left(2,7\right.$ a 5,4 $\left.\mathrm{mg} \mathrm{L}^{-1}\right)$ foram extremamente efetivas para o controle de $B$. cinerea e Penicillium expansum em maçãs, sem induzir fitotoxicidade. Vapor de vinagre branco, contendo $5 \%$ de ácido acético, reduziu a doença causada por $B$. cinerea em morangos de 50 para 1,4\% (SHOLBERG et al., 2000).

A eficiência da vaporização com ácido acético no controle das doenças, bem como a intensidade de fitotoxicidade, depende de vários fatores como: microrganismo-alvo e concentração de inóculo na superfície do fruto; concentração de ácido acético; tempo, temperatura e umidade de vaporização; quantidade de fruto e cultivar, e frequência de vaporização (SHOLBERG; GAUNCE, 1995; SHOLBERG et al., 2000; SHOLBERG et al., 2001). Sholberg e Gaunce (1995) mostraram que, quando a concentração de inóculo de $P$. expansum em maçãs aumentou, mantendo-se constante a concentração de ácido acético, o nível de controle diminuiu.

Uma vez utilizado para controle de fungos, os esporos são mais suscetíveis ao ácido acético sob condições de alta umidade relativa (SHOLBERG; GAUNCE, 1995), apresentando-se, portanto, como um potencial substituto ao dióxido de enxofre. A fumigação de cachos de uva com ácido acético $\left(8,0 \mathrm{mg} \mathrm{L}^{-1}\right)$, seguida pelo armazenamento em atmosfera modificada a $0^{\circ} \mathrm{C}$, reduziu a porcentagem de podridão causada por $B$. cinerea de 94 para $2 \%$, exercendo também o controle da degrana, além de não afetar o $\mathrm{pH}$, o odor e o sabor dos frutos (MOYLS et al., 1996). A fumigação com 2,0 ou $4,0 \mathrm{mg} \mathrm{L}^{-1}$ de ácido acético reduziu as podridões causadas por $B$. cinerea em uvas, maçãs, kiwis, peras e tomates inoculados com o patógeno e por $P$. expansum em maçãs, laranjas e peras inoculadas (SHOLBERG; GAUNCE, 1995). Sholberg et al. (1996), em estudo comparativo sobre os efeitos do vapor de ácido acético e o $\mathrm{SO}_{2}$ no controle de Botrytis e Penicillium, 
obtiveram redução no número de bagas com sintomas de mofo-cinzento pela fumigação com ácido acético $(8,0$ $\mathrm{mg} \mathrm{L}^{-1}$ ) em uvas 'Selection 494' (43\%) e 'Selection 651 ' (89\%), após seis semanas de armazenamento a 2 ou $5{ }^{\circ} \mathrm{C}$, respectivamente. Ainda, não observaram diferença significativa entre os tratamentos quanto às características dos cachos e bagas (peso dos cachos e bagas, sólidos solúveis, acidez titulável, $\mathrm{pH}$, cor e grau de desidratação da ráquis). A diferença de resposta entre as cultivares sugere especificidade na interação fruto-patógeno-volátil (ARCHBOLD et al., 1997).

De acordo com o exposto, o objetivo deste trabalho foi avaliar o efeito curativo e protetivo do vapor de ácido acético em uva 'Itália' contra $B$. cinerea na pós-colheita. $\mathrm{O}$ efeito in vitro do vapor de ácido acético sobre o crescimento micelial e a germinação de conídios do fungo também foram investigados.

\section{MATERIAL E MÉTODOS}

\section{de uva 'Itália' \\ Inoculação de Botrytis cinerea em cachos}

O patógeno de interesse (B. cinerea) foi isolado a partir de uvas com sintomas de mofocinzento, procedentes de vinhedo do Estado de São Paulo. Para inoculação, em cada cacho de uva foram feridas 10 bagas, fazendo-se um furo de $\pm 2 \mathrm{~mm}$ de profundidade, em cada baga, com o auxílio de uma microsseringa (Hamilton Co., Reno, Nevada, $100 \mu \mathrm{L}$ ). Depois de realizado o ferimento, os cachos foram inoculados por aspersão de suspensão de esporos, na concentração de $\pm 10^{5}$ conídios $\mathrm{mL}^{-1}$, determinada pela contagem em hemacitômetro, com adição de Tween 20, na proporção de uma gota para $100 \mathrm{~mL}$ da suspensão, de acordo com metodologia descrita por Romanazzi et al. (2002) e Thomas et al. (1988), com algumas modificações.

\section{Vaporização de ácido acético}

Para avaliação do efeito direto (curativo) do ácido acético glacial sobre o patógeno, no primeiro ensaio, cachos de uva 'Itália' maduros ( $>15^{\circ}$ Brix), provenientes do município de São Miguel Arcanjo$\mathrm{SP}$, foram inoculados, conforme descrito acima e, após quatro horas, vaporizados a 0,$0 ; 0,25 ; 0,5 ; 1,0$ ou 2,0 mL 100L $\mathrm{L}^{-1}$ vol. de câmara. Com o objetivo de avaliar o potencial do vapor de ácido acético glacial em proteger cachos de uva contra $B$. cinerea, no segundo ensaio, os cachos foram ou não vaporizados (1,0 mL de AA 100L ${ }^{-1}$ vol. de câmara) 24; 48; 72 ou $96 \mathrm{~h}$ antes da inoculação do fungo. Para vaporização, depositou-se o ácido acético glacial (densidade
$=1,05 \mathrm{~g} \mathrm{~mL}^{-1}$ ) em placas de Petri (no máximo 1,0 $\mathrm{mL}$ por placa para proporcionar total vaporização), as quais foram colocadas no interior de tambores herméticos de $200 \mathrm{~L}$, com circulação de ar. Os cachos de uva 'Itália' foram acondicionados em contentores no interior dos tambores, a uma distância aproximada de $20 \mathrm{~cm}$ acima das placas contendo o ácido acético glacial. O tempo de vaporização foi de 30 min a $25 \pm 1{ }^{\circ} \mathrm{C} / 70-80 \%$ UR (SHOLBERG et al., 1996; SHOLBERG, 1998). Após os tratamentos, os tambores foram abertos, proporcionando ventilação para a retirada do excesso de ácido acético. Os cachos foram acondicionados em caixas de papelão e armazenados a $25 \pm 1{ }^{\circ} \mathrm{C} / 80-90 \%$ UR, por até seis dias.

Avaliações de incidência (número de bagas infectadas) e severidade (porcentagem da área da baga infectada, determinada através de escala de notas) foram realizadas diariamente nas 10 bagas inoculadas de cada cacho. A escala de notas adotada para avaliação da severidade da podridão variou de 1 a 6 e foi elaborada com base na área da lesão, correspondendo a aproximadamente $<0,2 ; 0,5 ; 1,0$; 2,0 e $>3,0 \mathrm{~cm}^{2}$ da área da baga lesionada, equivalendo a $2 ; 5 ; 10 ; 20 ; 30$ e $50 \%$ da área, respectivamente. Os resultados foram expressos em índice de doença calculado através da fórmula: ID $(\%)=$ $\left\{\left[\left(\mathrm{n}_{1} \times 1\right)+\ldots+\left(\mathrm{n}_{6} \times 6\right)\right] \times(6 \times \mathrm{N})^{-1}\right\} \times 100$, onde, $\mathrm{n}_{1 \ldots 6}=$ $\mathrm{n}^{\circ}$ de bagas infectadas com a respectiva nota e $\mathrm{N}=$ $\mathrm{n}^{\circ}$ total de bagas inoculadas. O delineamento experimental utilizado foi o inteiramente casualizado, com 10 repetições, e um cacho de uva como unidade experimental. Para a avaliação do segundo experimento, adotou-se o arranjo fatorial $(2 \times 4)$. Os dados obtidos foram submetidos à análise de variância, e as médias, comparadas pelo teste de Tukey, a $5 \%$ de probabilidade. Para efeito de análise estatística, as médias foram transformadas em $\sqrt{\mathrm{x}+0,5}$. Além da comparação de médias, análises de regressão foram realizadas para verificar a relação entre dose e índice de doença.

\section{Efeito in vitro do vapor de ácido acético} sobre Botrytis cinerea

Visando a verificar o efeito do vapor de ácido acético glacial na germinação dos conídios de $B$. cinerea, placas de poliestireno contendo meio de cultivo ágar-água foram divididas em quatro quadrantes. Cada quadrante recebeu uma gota de suspensão de esporos $\left( \pm 10^{5}\right.$ conídios $\left.\mathrm{mL}^{-1}\right)$. Imediatamente, as placas (abertas), contendo a suspensão, foram submetidas a seis diferentes doses de ácido acético glacial $(0,0 ; 0,25 ; 0,5 ; 1,0 ; 2,0$ ou $4,0 \mathrm{~mL} 100 \mathrm{~L}^{-1}$ ), aplicado por volatilização, durante $30 \mathrm{~min}$, em tambores herméticos, com circulação 
de ar. Cada parcela foi representada por uma placa, sendo utilizadas seis repetições por tratamento, as quais foram mantidas no escuro a $\pm 22^{\circ} \mathrm{C}$ até a germinação dos conídios. Na avaliação, contaramse 50 conídios por quadrante, após $8 ; 24 ; 32 ; 48$ e $56 \mathrm{~h}$, pela observação em microscópio óptico. O conídio foi considerado germinado quando o tubo germinativo apresentou tamanho igual ou superior ao maior diâmetro do conídio (MERCIER et al., 2001).

Com o intuito de verificar o efeito do vapor de ácido acético glacial no crescimento micelial do patógeno, discos de micélio de $3 \mathrm{~mm}$ de diâmetro, retirados da borda de colônias com três dias de cultivo, foram transferidos para o centro de placas contendo meio Batata-Dextrose-Ágar (BDA). As placas foram mantidas $\mathrm{a} \pm 22^{\circ} \mathrm{C}$, por sete horas, antes da aplicação do ácido acético glacial $(0,0 ; 0,5 ; 0,5$;

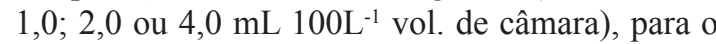
início do desenvolvimento do fungo. As placas, uma como unidade experimental e dez por tratamento, foram mantidas a $\pm 22^{\circ} \mathrm{C}$ sob alternância de luz $(12 \mathrm{~h})$. $\mathrm{O}$ crescimento micelial do fungo foi determinado diariamente, medindo-se o diâmetro da colônia em duas direções opostas, até que a colônia de um dos tratamentos atingisse a borda da placa (TERRY; JOYCE, 2000).

\section{RESULTADOS E DISCUSSÃO}

\section{(Ensaio 1)}

Tratamento pós-inoculação dos cachos

Os resultados obtidos no ensaio, onde diferentes doses de ácido acético glacial foram utilizadas para vaporização de cachos de uva 'Itália', previamente inoculados com $B$. cinerea, estão representados na Figura 1. Nota-se que, durante os dias de avaliação, todas as doses empregadas mostraram-se eficientes na redução do índice de doença comparadas à testemunha (não vaporizada).

Ao final do quarto dia de armazenamento, todos os cachos, independentemente do tratamento, apresentavam ráquis com coloração predominantemente marrom. Ainda, neste momento, os tratamentos não diferiram entre si quanto à cor das bagas (sistema de cor $L^{*} a^{*} b^{*}$ ) (dados não mostrados). Sholberg et al. (1996), da mesma forma, não verificaram diferenças significativas na cor das bagas e grau de secamento da ráquis em uvas vaporizadas com ácido acético. Os mesmos autores relatam ainda que uvas tratadas tiveram menor incidência de Botrytis do que o controle, sendo a vaporização com ácido acético glacial tão eficiente quanto a fumigação com $\mathrm{SO}_{2}$ aplicada em doses comerciais. Quanto ao efeito no controle de podridões pós-colheita, em diferentes trabalhos, os autores sugerem que o vapor de ácido acético reduza a contaminação superficial dos frutos (SHOLBERG; GAUNCE, 1995; SHOLBERG 1998; SHOLBERG et al., 2001).

Vista a eficiência de controle da doença no decorrer dos dias de avaliação obtida com todas as concentrações de vapor de ácido acético, optou-se por utilizar a dose de $1,0 \mathrm{~mL}$ para $100 \mathrm{~L}^{-1}$ de volume de câmara no segundo experimento (vaporização seguida de inoculação, efeito protetivo). Embora a dose de $2,0 \mathrm{~mL} 100 \mathrm{~L}^{-1}$ tenha apresentado valores médios menores de índice de doença, é sabido que doses acima do ideal podem causar escurecimento da epiderme de alguns frutos, conforme anteriormente relatado (SHOLBERG;GAUNCE, 1995; 1996) e, como ensaios prévios mostraram essa possibilidade em uva 'Itália', optou-se pela utilização de uma dose segura.

\section{(Ensaio 2)}

Tratamento pré-inoculação dos cachos

A Tabela 1 apresenta os dados de índice de doença obtidos em cachos de uva 'Itália' submetidos ao tratamento com vapor de ácido acético $24 ; 48 ; 72$ ou $96 \mathrm{~h}$ antes da inoculação com $B$. cinerea. Verificou-se que, independentemente do intervalo de tempo entre o tratamento e a inoculação, cachos de uva vaporizados com 1,0 mL $100 \mathrm{~L}^{-1}$ apresentaram índice de doença significativamente menor do que os não vaporizados. Pode-se constatar ainda que no segundo e terceiro dias de armazenamento, independentemente de os cachos terem sido vaporizados ou não, quando inoculados 48 e $72 \mathrm{~h}$ após a transferência para condições ambiente $\left(25 \pm 1{ }^{\circ} \mathrm{C} / 80-90 \%\right.$ UR), apresentaram índices de doença significativamente menores do que os vaporizados 24 e $96 \mathrm{~h}$ antes da inoculação.

No quarto dia de avaliação, cachos vaporizados 48 e $72 \mathrm{~h}$ antes da inoculação apresentaram o menor índice de doença, diferindo significativamente dos cachos não vaporizados ou vaporizados 24 ou 96 h antes da inoculação com o patógeno.

A necessidade de certo período de tempo (horas, dias) para que ocorra o acúmulo de fitoalexinas e desenvolvimento de resistência em uva tratada com irradiação UV-C já foi demonstrada por Langcake e Pryce, em 1977. Desta forma, a resposta dos cachos de uva 'Itália' à inoculação, em diferentes momentos após a vaporização com ácido acético glacial, indica um efeito protetivo, merecendo novas investigações dos mecanismos de resistência da fruta.

Com base nos resultados de ambos os ensaios in vivo, inoculação pré ou pós-tratamento, pode-se inferir que o mecanismo de inibição da doença, neste 
caso, foi através do efeito direto do ácido acético sobre o desenvolvimento do patógeno. Na literatura, não há relato do possível efeito do vapor de ácido acético em induzir mecanismos de defesa em frutos contra patógenos. Ainda, é possível inferir que o efeito do produto em reduzir o índice de doença causada por B. cinerea em uva 'Itália', quando inoculada após o tratamento, pode ser atribuído ao efeito de desinfecção da superfície das bagas, podendo haver resíduo do ácido, ainda que em baixas concentrações.

Efeito in vitro do vapor de ácido acético sobre Botrytis cinerea

O vapor de ácido acético glacial reduziu significativamente o crescimento micelial e a germinação de conídios de $B$. cinerea. Assim como em outros trabalhos (SHOLBERG; GAUNCE, 1995), o vapor de ácido acético inibiu completamente a germinação de conídios deste patógeno.

Quando os conídios foram vaporizados, doses maiores que $0,5 \mathrm{~mL} 100 \mathrm{~L}^{-1}$ vol. de câmara inibiram completamente a germinação dos mesmos, com exceção da dose de $0,25 \mathrm{~mL} 100 \mathrm{~L}^{-1}$, com a qual se verificou pequena e desuniforme porcentagem de germinação (reduziu a germinação de 100 para $30 \%$, após 32 horas da exposição aos vapores do ácido); porém, aumentando-se o tempo de vaporização de 30 para $60 \mathrm{~min}$, obteve-se redução de $100 \%$ na germinação dos conídios. Sholberg e Gaunce (1995) mostraram que baixas concentrações de vapor de ácido acético preveniram a germinação de conídios de $B$. cinerea e $P$. expansum. Ainda, Sholberg et al. (2000) relatam que o número de lesões causadas por P. expansum em maçãs diminuiu exponencialmente com o aumento no tempo de fumigação com vinagres contendo diferentes concentrações de ácido acético; entretanto, a fumigação com altas concentrações de vinagre por um curto período de tempo não foi eficiente em prevenir a infecção causada por $B$. cinerea em morangos.
Quanto ao efeito do vapor de ácido acético glacial sobre o crescimento micelial de $B$. cinerea, verificou-se que todas as concentrações reduziram significativamente o crescimento das colônias do fungo (Figura 2). Sob tal aspecto, Abd-El-Kareem (2001) constatou que o ácido acético, nas concentrações de $4 ; 6$ ou $8 \mu \mathrm{L} \mathrm{L}^{-1}$, inibiu completamente o crescimento micelial de B. cinerea e Penicillium sp.. Para Rhizopus stolonifer e Alternaria sp., as concentrações de 6 ou $8 \mu \mathrm{L} \mathrm{L}^{-1}$, respectivamente, foram as que inibiram completamente o desenvolvimento dos fungos.

Pelo fato de o ácido acético ser um constituinte natural dos alimentos, não há um limite determinado de ingestão diária pelas pessoas segundo a Food and Agriculture Organization (FAO), ao contrário do que acontece com o $\mathrm{SO}_{2}$, cujo limite de tolerância é de $10 \mu \mathrm{g} . \mathrm{g}^{-1}$ (Sholberg et al., 1996). Neste sentido, o vapor de ácido acético glacial é um potencial substituto ao $\mathrm{SO}_{2}$ comumente utilizado no controle de podridões em pós-colheita de uvas de mesa, mantidas sob armazenamento refrigerado.

De acordo com Sholberg e Gaunce (1996), a fumigação com ácido acético tem potencial para controle de doenças na pós-colheita se infecções quiescentes forem controladas ainda no campo. Porém, como demonstrado neste e em outros trabalhos recentes (PERERA;KARUNARATNE, 2001), a vaporização com compostos voláteis, particularmente ácido acético, apresenta-se como uma medida promissora para controle de infecções quiescentes na pós-colheita. Dessa forma, o uso do vapor de ácido acético é uma opção viável que pode complementar a eficiência de outros tratamentos em pós-colheita, principalmente quando medidas alternativas aos fungicidas sintéticos são requeridas (Sholberg et al., 2001). 


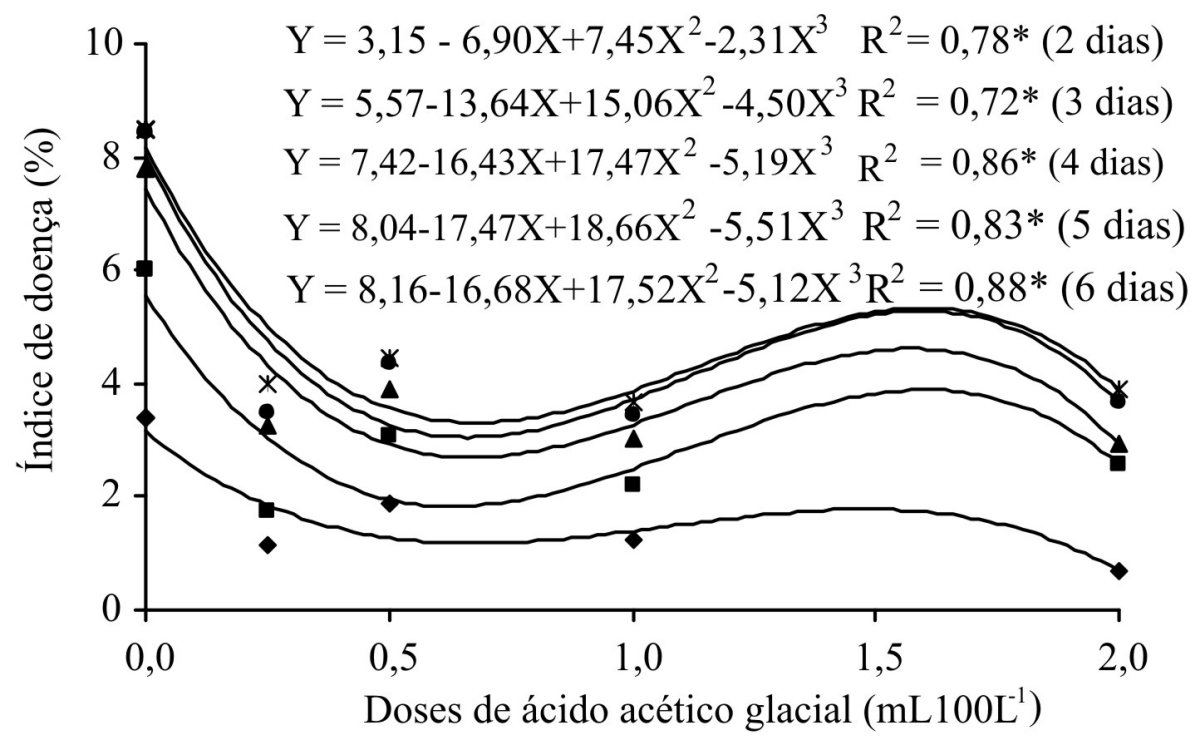

- 2 - 3 Dias de armazenamento $\bullet 5 \quad * 6$

FIGURA 1 - Índice da doença mofo-cinzento (\%), causada por Botrytis cinerea, em cachos de uva 'Itália' tratados com diferentes concentrações de ácido acético, quatro horas após a inoculação com o patógeno. Média de dez repetições. Linha contínua $=$ dados da regressão, e pontos $=$ dados originais, representam os dias após a inoculação (dias de armazenamento).

* Significativo a $5 \%$ de probabilidade.

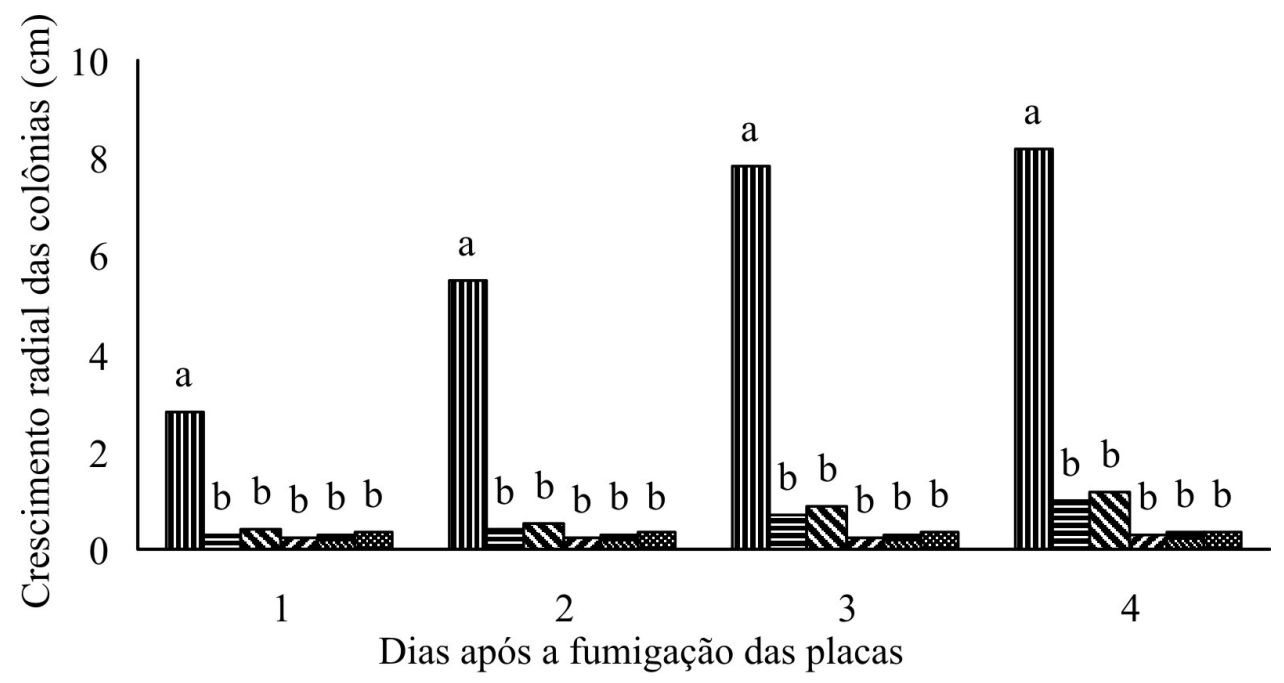

血 $0,0 \equiv 0,25 \mathbf{x} 0,5 \quad \bullet 1,0 \quad \mathbf{w} 2,0 \quad 4,0$

Concentrações de ácido acético glacial $\left(\mathrm{mL} \mathrm{100 \textrm {L } ^ { - 1 } )}\right.$

FIGURA 2 - Crescimento micelial de Botrytis cinerea expostos a diferentes concentrações de ácido acético. 
TABELA 1 - Efeito do vapor de ácido acético (AA, 1,0 mL 100L $\left.\mathrm{L}^{-1}\right)$ sobre o índice (\%) da doença mofocinzento, em cachos de uva 'Itália', inoculados com Botrytis cinerea após a vaporização e armazenados a $25 \pm 1{ }^{\circ} \mathrm{C} / 80-90 \%$ UR.

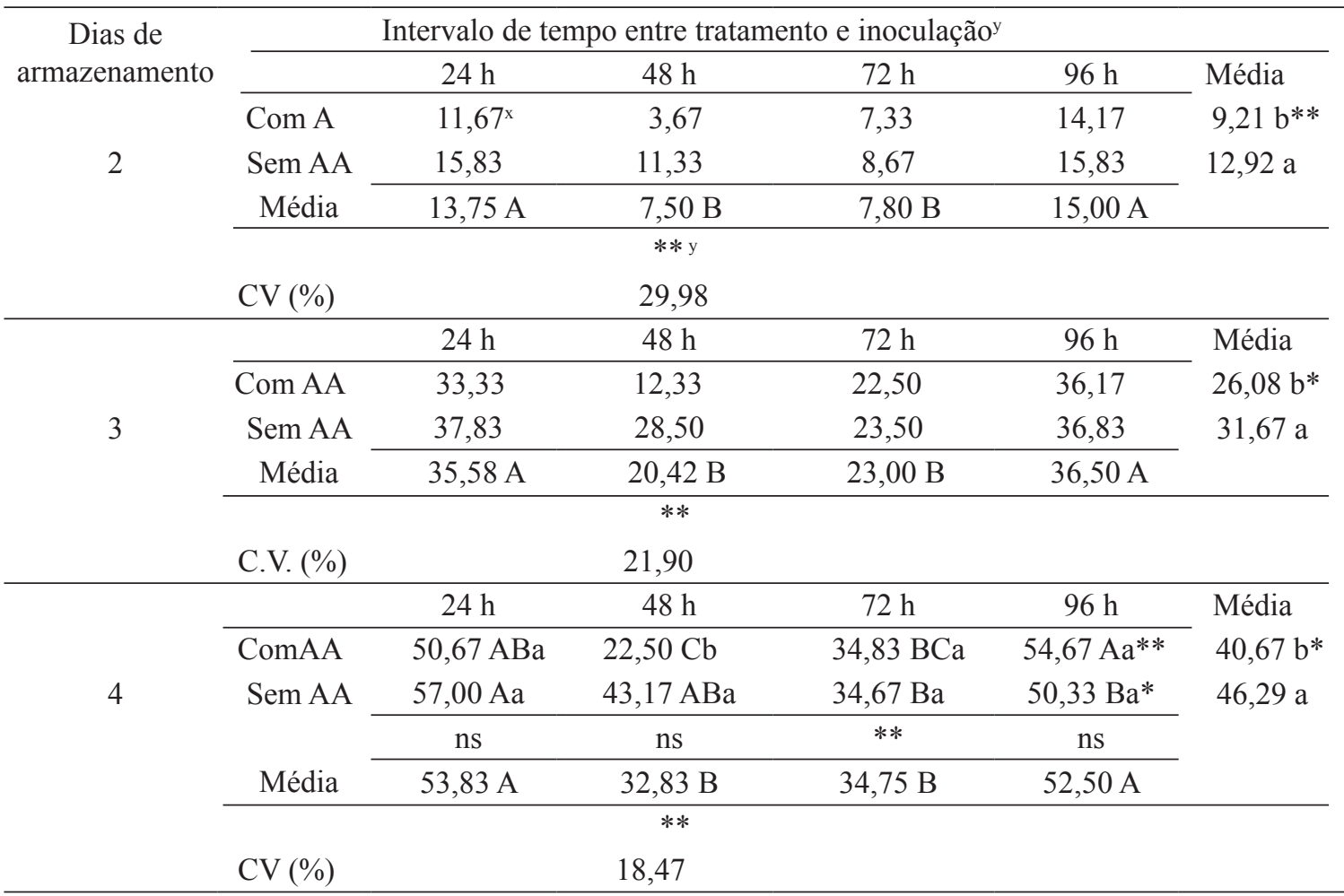

x Média de dez repetições. Médias seguidas da mesma letra maiúscula na linha e minúscula na coluna não diferem estatisticamente entre si $(P \leq 0,05)$. Dados originais foram transformados em $\sqrt{\mathrm{x}+0,5}$, para análise estatística.

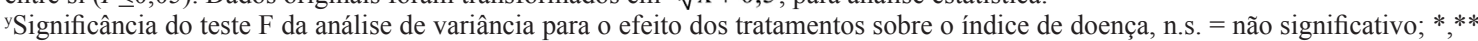
$=$ significativo a 5 e $1 \%$ de probabilidade, respectivamente.

\section{CONCLUSÃO}

O vapor de ácido acético glacial reduz a podridão de Botrytis cinerea em uva 'Itália', tanto em cachos previamente inoculados, como em cachos inoculados após o tratamento. In vitro, o ácido acético retarda o crescimento micelial e inibe completamente a germinação de conídios de $B$. cinerea .

\section{REFERÊNCIAS}

ABD-EL-KAREEM, F. Fumigation of table grapes with acetic acid vapours for controlling gray mold decay. Egyptian Journal Phytopatology, Dokki, v. 29, n. 1, p. 89-98, 2001.

ARCHBOLD, D. D.; HAMILTON-KEMP, T. R.; BARTH, M. M.; LANGLOIS, B. E. Identifying natural volatile compounds that control gray mold (Botrytis cinerea) during postharvest storage of strawberry, blackberry, and grape. Journal of Agricultural and Food Chemistry, Washington, v. 45, n. 10, p. 4032-4037, 1997.
BENATO. E. A. Cuidados na colheita, manuseio e conservação de uva de mesa. In: REGINA. M. A. (Coord.). SIMPÓSIO MINEIRO DE VITICULTURA E ENOLOGIA, 1., 2002, Andradas. Viticultura e enologia: atualizando conceitos... Caldas: EPAMIG-FECD, 2002. p. 121-135.

BULIT, J.; DUBOS, B. Botrytis bunch rot and blight. In: PEARSON, R. C.; GOHEEN, A. C. (Ed.). Compendium of grape diseases. St. Paul: APS Press, 1990. p. 13-15.

CIA, P.; PASCHOLATI, S. F.; BENATO, E. A. Indução de resistência no manejo de doenças pós-colheita. In: RODRIGUES, F. A.; ROMEIRO, R. S. (Org.). Indução de resistência em plantas a patógenos. In: REUNIÃO BRASILEIRA SOBRE INDUÇÃO DE RESISTÊNCIAEM PLANTAS A PATÓGENOS, 3., 2007. Anais... Viçosa: UFV, 2007. v. 1, p. $245-$ 268. 
DIAS, M. S. C.; SOUZA, S. M. C.; PEREIRA, A. F. Principais doenças da videira. Informe Agropecuário, Belo Horizonte, v.19, n.194, p.76-84, 1998.

FOOD AND DRUG ADMINISTRATION. Sulfites: an important food safety issue. Disponível em: $<$ http://vm.cfsan.fda.gov/ dms/fssulfit.html $>$. Acesso em: 19 nov. 2003.

GONZALEZ, U. A.; OREA, J. M.; MONTERO, C.; JIMÉNEZ, J. B.; GONZÁLEZ, J. L.; SÁNCHEZ, A.; DORADO, M. Improving postharvest resistance in fruits by external application of trans-resveratrol.

Journal of Agricultural and Food Chemistry, Washington, v. 51, n. 1, p. 82-89, 2003.

LANGCAKE, P.; PRYCE, R. The production of resveratrol and the viniferins by grapevines in response to ultraviolet irradiation. Phytochemistry, Oxford, v. 16, n.8, p. 1193-1196, 1977.

MARQUENIE, D.; LAMMERTYN, J.; GEERAERD, A. H.; SOONTJENS, C.; VAN IMPE, J. F.; NICOLAI, B. M.; MICHIELS, C. W. Inactivation of conidia of Botrytis cinerea and Monilinia fructigena using UV-C and heat treatment. International Journal of Food Microbiology, Amsterdam, v. 74, n. 1-2, p. 27-35, 2002.

MERCIER, J.; BAKA, M.; REDDY, B.; CORCUFF, R.; ARUL, J. Shortwave ultraviolet irradiation for control of decay caused by Botrytis cinerea in Bell pepper: induced resistance and germicidal effects. Journal of the American Society for Horticultural Science, Alexandria, v. 126, n. 1, p. 128-133, 2001.

MOYLS, A. L.; SHOLBERG, P. L.; GAUNCE, A. P. Modified-atmosphere packaging of grapes and strawberries fumigated with acetic acid. HortScience, Alexandria, v. 31, n.3, p.414-416, 1996.

PERERA, O. D. A. N.; KARUNARATNE, A. M. Response of bananas to postharvest acid treatments. Journal of Horticultural Science \& Biotechnology, Kent, v. 76, n. 1, p. 70-76, 2001.
ROMANAZZI, G.; NIGRO, F.; IPPOLITO, A.; VENERE, D. I.; SALERNO, M. Effects of pre and postharvest chitosan treatments to control storage grey mold of table grapes. Journal of Food Science, Chicago, v. 67, n. 5, p. 1862-1867, 2002.

SHOLBERG, P. L. Fumigation of fruit with shortchain organic acids to reduce the potential of postharvest decay. Plant Disease, St Paul, v. 82, n. 6, p. 689-693, 1998.

SHOLBERG, P. L.; CLIFF, M.; MOYLS, A. L. Fumigation with acetic acid vapor to control decay of stored apples. Fruits, Cambridge, v. 56, n. 5, p. 355-366, 2001.

SHOLBERG, P. L.; GAUNCE, A. P. Fumigation of fruit with acetic acid to prevent postharvest decay. HortScience, Alexandria, v.30, n.6, p.1271-1275, 1995.

SHOLBERG, P. L.; GAUNCE, A. P. Fumigation of stonefruit with acetic acid to control postharvest decay. Crop Protection, Oxford, v.15, n.8, p.681686, 1996.

SHOLBERG, P. L.; HAAD, P.; HOCKING, R.; BEDFORD, K. The use of vinegar vapor to reduce postharvest decay of harvested fruit. HortScience, Alexandria, v. 35, n. 5, p. 898-903, 2000.

SHOLBERG, P. L.; REYNOLDS, A. G.; GAUNCE, A. P. Fumigation of table grapes with acetic acid to prevent postharvest decay. Plant Disease, St. Paul, v. 80, p. 1425-1428, 1996.

TERRY, A. L.; JOYCE, D. C. Suppression of grey mould on strawberry fruit with the chemical plant activator acibenzolar. Pest Management Science, Sussex, v. 56, n. 11, p. 989-992, 2000.

THOMAS, C. S.; MAROIS, J. J.; ENGLISH, J. T. The effects of wind speed, temperature, and relative humidity on development of aerial mycelium and conidia of Botrytis cinerea on grape. Phytopathology, St. Paul, v. 78, p. 260-265, 1988. 